\title{
The effect of E-Service category on Consumers' Perceived Risk
}

\author{
Xiaoyun Deng ${ }^{* \# 1}$, Yiwen Chen ${ }^{* 2}$, Jinjin $\mathrm{Gao}^{* \# 3}$, Xiang sun ${ }^{* 4}$ \\ *Institute of Psychology, Chinese Academy of Sciences \\ 4 A Datun Road, Chaoyang District, Beijing, P.R. China \\ ${ }^{\#}$ Graduate University of Chinese Academy of Sciences \\ $19 A$ Yuquan Road, Shi Jingshan District, Beijing, P.R. China \\ 1dengxy@psych.ac.cn \\ chenyw@psych.ac.cn \\ 3 gaojinjinjob@163.com \\ ${ }^{4}$ sunx@psych.ac.cn
}

\begin{abstract}
Whether consumers' risk perception differs or not when purchasing different services online? 115 participants were investigated to discover the differences in the lab experiment, and the results indicated that: a) Consumers perceived higher risk in buying professional services than mass services, interactive services, and supporting services online, while the differences among the latter three services were not significant. b) The constructs of risk perception in different E-services differ: consumers perceived performance risk when purchasing mass services; financial risk and psychological risk were perceived in interactive services; when buying the supportive services, financial risk was perceived; financial risk, social risk and psychological risk were perceived in buying professional services online.
\end{abstract}

\section{Introduction}

It was reported that the number of people buying online in 2009 came 88 million in China, with the raising rate of $38.9 \%$ [1]. The mainstream of business online is not service buying, however, the transaction of the service online increased largely recently, especially the tourist ordering, with the growth rate of $77.9 \%$ [2].It is believed that the population and business of E-service will increase faster, with the diversifying of B2C (Business-to-Consumer) and $\mathrm{C} 2 \mathrm{C}$ (Consumer-to-Consumer) market in China.

Perceived risk can be considered as a function of the uncertainty and the possible unpleasantness of the potential outcomes in a particular transaction [3], which is proven to strongly influence consumers' actual behavior online. It is believed that risk perception is the consequences of subjective evaluation of risk sources, which objectively exist in Ecommerce. Since that, it is necessary to identify the risk sources causing specific risk perception in order to reduce them. Specific risk source is found to bring specific risk perception in Lim's study, and product is also found to be one of the risk sources in E-commerce [4]. Due to different information offering by Eservices, consumers' perceptions of risk are supposed to be different. This idea is supported in Jiunn-Woei Lian's study, which reported that service type influenced the relationship between consumers' characteristics and attitudes to online shopping [5]. However, there is no study explaining the differences of consumers' risk perceptions when purchasing different services online. Due to the above reasons, we assumed that it was necessary to investigate the effect of service category to perceived risk.

According to sung, the E-services was divided into four categories: the Mass services, the Interactive Services, the Supporting Services, and the Professional Services [6]. The E-services were categorized by two dimensions which were proportion of on-line services and need of on-line interaction as, and the level of them advance gradually in the four categories. Due to increasing need in off-line cooperation, the information offered online decreases in the four categories, and the technological requirements also increase as a result of increasing need in on-line interaction. Therefore, we predict that:

H1: The risk perception in buying the four kinds of E-services increases gradually.

Perceived risk has a multi-dimensional construct in E-Commerce, including seven dimensions which are financial risk, performance risk, privacy risk, 
psychological risk, time-loss risk, social risk and physical risk [7]. According to the multi-dimensional perspective, the construct differs with the changing of shopping contexts and product descriptions. So we predict that:

H2: The construct of perceived risk is different when consumers purchase different E-services.

There are three kinds of research paradigms in perceived risk: technology paradigm, psychometrical paradigm and social-cultural paradigm [8]. Psychometrical paradigm is common, however, considered to be neglectful of social and political influences. In the study, the researchers simulate real internet shopping in the laboratory, using duration of services' information process to scale risk perception. It is believed that risk perception causes more effort in processing product description, in doing so, duration of evaluation prolonged. The idea was supported in the study of Ellen, who reported consumers gave negative judgment in the product, in which they spent more [9]. Besides the experimental measurement, questionnaire also was used in the study to scale the risk perception, so as to validate whether duration of processing is appropriate for measuring risk perception.

\section{Method}

\subsection{Pretest}

2.1.1. Stimulus. 22 E-services were divided into four categories by 12 experts according to sung, each category containing 5 specific services. 31 participants were chosen randomly to sequence the 5 specific services in each category according to how much they are concerned about and familiar with them. Four Eservices are determined as stimulus, including the mass service (pay E-mail), the interactive service (Ebanking), the supportive service (gift service), and professional service (online medical consultation).

2.1.2. Shopping context and Service descriptions. 24 consumers were interviewed to discover which information of services they are interested in and to identify the shopping context promoting their shopping. According to the records of interviews, researchers encoded the information mentioned most in 1500 words and identify the context that can really stimulate the consumers' motivation of shopping.

\subsection{Participants and Design}

Participants were 60 graduates and undergraduates who experienced online shopping at least once. The design was between-subjects design with service category as independent variable and browsing duration, clicking times and the score of perceived risk questionnaire as dependent variables.

\subsection{Procedure}

The experiment was conducted on computer in the behavioral lab. It constitutes two parts, the first part is a practice phase, and the second part is the real test. In the practice phase, after the instructions about shopping context presented, the services description would be presented. Participants could click to choose to "buy at once" or to "buy later". Those choosing to "buy at once" will respond to the perceived risk questionnaire and then go to real test. Conversely, those choosing to "buy later" will be reminded that "You still have one product to buy, please buy it at once or quit". Then no matter which be chosen, participants would respond the perceived risk questionnaire and go to the real test. In the real test, the participants would choose four kinds of services which are randomly presented according to the same procedure with the first part. Having been presented all services for one time, the subjects will be reminded if there were any services left to be chosen. It will not terminate until all services be chosen.

The consumers are able to click the information button to learn about each service, the total clicking times and the browsing duration will be recorded in the end of the experiment. The questionnaire elaborated by DR You and her colleagues is revised by researchers to form a new questionnaire. The researcher incorporated several questions with approximate validity and simplified the original questionnaire from 28 items to 22 items. The new questionnaire constitutes two 7 points scales, a subscale of 7 dimensions and the other subscale of general risk perception. The $\alpha$-coefficient of each dimension in the questionnaire and of general risk is $0.60 \sim 0.94$.

\section{Results}

\subsection{Browsing duration}

Browsing duration refers to the time spending in evaluating service description, of which the four services are: paying mail $(M=40.47)$, online banking $(M=45.82)$, gift service $(M=44.84)$, and online medical consultation $(M=59.18)$. We estimated an ANOVA using service category to predict browsing duration, $F(3,57)=9.19, p<0.001$. T-tests were conducted to compare the four kinds of E-services, and results indicated that online medical consultation is significantly different from the other three services, and the differences among the three services are not significant. (See table 1) 
Table 1. Compare between four services (Browsing duration)

\begin{tabular}{clcc}
\hline & Service & $M D$ & $t$ \\
\hline PM & EB & -5.35 & -2.23 \\
& GS & -4.38 & -1.21 \\
& OMC & -18.72 & $-4.91^{* *}$ \\
EB & GS & 0.98 & 0.47 \\
& OMC & -13.37 & $-2.90^{*}$ \\
GS & OMC & -14.34 & $-2.75^{*}$ \\
\hline Note: P<0.05 "P<0.001 & \multicolumn{3}{c}{} \\
\multicolumn{4}{c}{ PM-Pay E-mail; EB-E-banking; GS-Gift service; } \\
\multicolumn{4}{c}{ OMC-Online medical consultation }
\end{tabular}

\subsection{Clicking times}

Click times, the times of clicking information button, of which the four services are: paying mail $(M$ = 4.77), E-banking $(M=5.02)$, gift service $(M=4.88)$, and online medical consultation $(M=5.57)$. We estimated an ANOVA using service category to predict click times, $F(3,57)=6.52, p<0.001$. T-tests were conducted to compare the click times of the four categories, the results showed that significant difference existed between the online medical consultation and the other three services, and the differences among the other three are not significant. (See table 2)

Table 2. Compare between four services (Clicking time)

\begin{tabular}{llcc}
\hline & Service & $M D$ & $t$ \\
\hline PM & EB & -0.25 & -1.79 \\
& GS & -0.12 & -0.59 \\
& OMC & -0.80 & $-3.23^{*}$ \\
\multirow{2}{*}{ EB } & Gift service & 0.13 & 0.94 \\
& OMC & -0.55 & $-2.82^{*}$ \\
GS & OMC & -0.68 & $-3.01^{*}$ \\
\hline
\end{tabular}

Note: $P<0.05 " P<0.001$

The abbreviations for service are same as table 1.

\subsection{General risk}

General risk, the scores of general perceived risk questionnaire, of which the four services are: paying mail $(M=3.93)$, E-banking $(M=3.74)$, gift service $(M$ =4.02), and online medical consultation $(M=4.58)$. We estimated an ANOVA using service category to predict general risk, $F(3,57)=6.17, p<0.001$. To compare the general risk of four categories, t-tests were conducted and the results indicated that online medical consultation is significantly different from the other three services, and the differences among the other three are not significant. (See table 3)

Table 3. Compare between four services (General risk)

\begin{tabular}{llcc}
\hline & Service & $M D$ & $t$ \\
\hline PM & EB & 0.19 & 0.92 \\
& GS & -0.08 & -0.40 \\
& OMC & -0.64 & $-3.07^{*}$ \\
EB & GS & -0.28 & -1.49 \\
& OMC & -0.83 & $-4.08^{* *}$ \\
GS & OMC & -0.56 & $-2.74^{*}$ \\
\hline
\end{tabular}

Note: $P<0.05 " P<0.001$

The abbreviations for service are same as table 1.

It should be noticed that experimental results (decision time and click times) indicate the risk of Ebanking is higher than that of pay E-mail and gift service, however, the results shown in questionnaire reverse.

\subsection{The construct of perceived risk in four services}

A regression analysis was conducted to determine general risk by seven dimensions of perceived risk.

Only performance risk is significant in the regression analysis, which means that consumers perceived performance risk in purchasing pay E-mail. (See table 4)

Table 4. Regression analysis for general risk (Pay E-mail)

\begin{tabular}{lcc}
\hline Perceived risk & $\beta$ & $t$ \\
\hline Financial risk & 0.18 & 1.74 \\
Social risk & 0.20 & 1.85 \\
Time-loss risk & 0.13 & 0.93 \\
Physical risk & -0.00 & -0.04 \\
Performance risk & 0.53 & $4.86^{* *}$ \\
Psychological risk & 0.14 & 1.26 \\
Privacy risk & -0.14 & -1.50
\end{tabular}

Note: $P<0.05 " P<0.001$

In the regression analysis for E-banking, the financial risk and psychological risk are significant to 
predict general risk (See table 5). It means that consumers perceived that two dimension risk in Ebanking.

Table 5. Regression analysis for general risk (E-banking)

\begin{tabular}{lcc}
\hline Perceived risk & $\beta$ & $t$ \\
\hline Financial risk & 0.37 & $2.50^{*}$ \\
Social risk & -0.15 & -1.41 \\
Time-loss risk & 0.02 & 0.12 \\
Physical risk & -0.03 & -0.35 \\
Performance risk & 0.04 & 0.27 \\
Psychological risk & 0.48 & $3.33^{* *}$ \\
Privacy risk & 0.21 & 1.83 \\
\hline
\end{tabular}

Note: $P<0.05 " P<0.001$

The results of regression analysis illustrate that general risk is significant predicted only by financial risk (See table 6). That means consumers pay close attention to financial risk in purchasing gift service online.

Table 6. Regression analysis for general risk (Gift service)

\begin{tabular}{lcc}
\hline Perceived risk & $\beta$ & $t$ \\
\hline Financial risk & 0.39 & $2.04^{*}$ \\
Social risk & 0.00 & 0.01 \\
Time-loss risk & 0.19 & 1.17 \\
Physical risk & 0.09 & 0.87 \\
Performance risk & 0.14 & 0.78 \\
Psychological risk & 0.02 & 0.19 \\
Privacy risk & 0.09 & 0.69
\end{tabular}

Note: $P<0.05 " P<0.001$

The financial risk, social risk and psychological risk significantly predict general risk in the regression analysis (See table 7). The results manifested that consumers perceived financial risk, social risk, and psychological risk in purchasing online medical consultation.

Table 7. Regression analysis for general risk (Online medical consultation)

\begin{tabular}{lcc}
\hline Perceived risk & $\beta$ & $t$ \\
\hline Financial risk & 0.64 & $5.86^{* *}$ \\
Social risk & -0.31 & $-3.89^{* *}$ \\
Time-loss risk & 0.16 & 1.81 \\
Physical risk & -0.09 & -1.20 \\
Performance risk & 0.07 & 0.95 \\
Psychological risk & 0.45 & $4.64^{* *}$ \\
Privacy risk & -0.06 & -0.76 \\
\hline
\end{tabular}

Note: $" P<0.05 " P<0.001$

In sum, the above results indicate that the construct of perceived risk vary in different services, which means $\mathrm{H} 2$ is confirmed.

\section{Discussion}

In this study, the researchers inducted two kinds of methods, the experimental methods and the questionnaire measurement, to measure the risk perception. Two specific methods are included in the experimental measurements, the browsing duration and clicking times. In the study, the results indicated that the two experimental methods were accordant with each other. Besides, researchers conducted a correlation analysis between the two measurements, found that the correlation efficiency is between $0.3 \sim 0.51, p<0.01$, which also supports that the two methods were consistent with each other.

The experimental results are basically consistent with questionnaire, however, the inconsistency exists. The results of experiment indicated that risk perception of interactive service (E-banking) is higher than that of the supportive service (gift service), however, results converse in questionnaire. The probable reason is lacking of control in time pressure in the study. According to ELM perspective, consumers' information processing is influenced by the cognitive ability, the motivation and the opportunity of processing. In the study, researchers controlled cognitive ability and motivation by giving the same service descriptions and the same shopping context, however, the time pressure uncontrolled may result in the prolonging browsing duration for interactive service.

The risk perception of online medical consultation is significantly different with that of pay E-mail, Ebanking and gift services. But no significant differences among the latter three services exist, which may be caused by that the student participants are familiar with the three services.

In the study, the hypothesis that different services have different risk construct is validated. Only performance risk is perceived in mass service, which may due to that the mass service is so generally accepted that consumers always only concern about the performance when purchasing it online. Besides, the results show that the financial risk cannot be perceived in mass service, for which the possible explanation is the low price generally. The psychological risk is perceived in interactive and professional service other than the mass service and supportive service, which can be explained by that the former two services are so more complicated to master than the latter services that consumers feel more anxious when purchasing them.

The results that different services have different risk construct contribute to perceived risk theories and can help company to distinguish differences of services online. Making good use of that different risk 
constructs were found in different services can bring about extra competitive advantages when now products are generally homogeneous.

The limitation of the study is lacking control in time pressure. Researchers allowed participants to chose "buy later" in order to simulate the real buying behavior. However, the results showed that participants' browsing duration prolonged when purchasing professional services. It reminds us that in future research, researchers should consider how to balance the simulation of real purchase and control of time pressure.

\section{Acknowledgement}

This study is founded by the Knowledge Innovation Project of the Chinese Academy of Sciences (Grant NO.KSCX2-YW-R-130) and special fund for coconstruction project of Beijing Education Council. The corresponding author is Yiwen Chen, and his available e-mail is chenyw@psych.ac.cn.

\section{References}

[1] China Internet Network Information Center (CNNIC), "The market research report about business of E-commerce in China", 2009, Available: Http://www.cnnic.net.cn/.
[2] China Internet Network Information Center (CNNIC), "The statistic report about internet development in China", 2010, Available: Http://www.cnnic.net.cn/.

[3] Murray KB, "A test of services marketing theory: consumer information acquisition activities", Journal, Journal of Marketing, USA, 1991, 55(1), pp. 10-25.

[4] Nena Lim, "Consumers' perceived risk: sources versus consequences", Journal, Electronic Commerce Research and Applications, USA, 2003, 2(3), pp.216-228.

[5] Jiunn-Woei Lian, Tzu-Ming Lin, "Effects of consumer characteristics on their acceptance of online shopping: Comparisons among different product tapes", Journal, Computers in Human Behavior, USA, 2008, 24, pp. 48-65.

[6] Sung-Eui Cho, Kwangtae Park, "Empirical taxonomy of services and service products in electronic commerce", Journal, Electronic Commerce Research and Applications, USA, 2002, 1, pp. 339-350.

[7] X Sun, D You, Y Chen, E Wang, "The Effects of Consumer-related Factors on the Perceived Risk in Online Shopping", Journal, Chinese Journal of ergonomics, China, 2005, 11(4).

[8] S. Mun, "The perception of risk in sport activities," Doctor. thesis, College of Education, Florida, USA, Jun. 2004

[9] Ellen, C. G., and Julie, A. E, "Cognitive effort, affect, and choice", Journal of Consumer Research, USA, 24(2), pp. $147-15$. 